\title{
A Case of Bilateral Cleft Lip Repair Using Pfeifer's Wavy-Line Incision with Long Term Follow Up
}

\author{
K. Harsha Vinay Durga Karthik ${ }^{1 *}$, Rayadurgam Venkata Kishore ${ }^{2}$
}

${ }^{1}$ Post Graduate Student, Narayana Dental College \& Hospital, Nellore, Andhra Pradesh, India

${ }_{2}^{2}$ Professor, Department of Oral Maxillofacial Surgery, Narayana Dental College \& Hospital, Nellore, Andhra Pradesh, Pin-524002, India

\author{
DOI: $10.36347 /$ sjds.2020.v07i04.001 \\ | Received: 21.03.2020 | Accepted: 30.03.2020 | Published: 05.04.2020 \\ *Corresponding author: K. Harsha Vinay Durga Karthik
}

Abstract

Bilateral cleft lip is a congenital anomaly where repairing it is a challenging task for the surgeon. The present case report highlights a surgical technique which has given superior aesthetic results with long term follow up of 6 years.

Keywords: Cleft, bilateral cleft lip, pfeifer's technique of cleft lip repair.

Copyright @ 2020: This is an open-access article distributed under the terms of the Creative Commons Attribution license which permits unrestricted use, distribution, and reproduction in any medium for non-commercial use (NonCommercial, or CC-BY-NC) provided the original author and source are credited.

\section{INTRODUCTION}

Cleft is a congenital abnormal space or gap in upper lip or alveolus or palate. Incidence of cleft lip with or without palate has an average birth prevalence of 1: 700. Among them incidence of bilateral cleft lip is rare in occurrence with incidence of 1 in 6500 live cleft births. The present case is referred to the dept of OMFS from the dept of paediatrics and the child is ruled out for all other anomalies and fitness is obtained and operated using pfeifer's technique and followed for a period of six years. Lip and nasal parameters are evaluated.

\section{PRESENTATION OF THE CASE}

A 6 months old male child reported to dept with bilateral cleft lip with anteriorly projected premaxilla and the child is operated under GA using pfeifer's technique and pre operatively and post operatively evaluated for lip and nasal parameters i.e lip length balance, White line alignment, vermellion equality, cupid's bow, pout of the lip and nose dorsum, ala, nostril size, sill, nose tip and columella.

All the parameters' are considered as poor pre operatively and scores are given post operatively according to their outcome.

\section{SURGICAL PROCEDURE}

After sketching of waves, $2 \%$ lignocaine with adrenaline $(1: 80,000)$ was used for administration of bilateral infraorbital blocks and infiltrated locally over the prolabium. Incisions were made along the markings using no. 11 surgical blade involving skin and subcutaneous tissue on the prolabium and lateral lip elements. Incision is extended upto the level of vomeromaxillary suture bilaterally on prolabium. Sterile tissue is excised taking care to avoid deficiency of tissue for normal closure. On prolabium, dissection carried out in subcutaneous plane and subperiostal layer is raised up to the nasal septum (muscle is absent in complete bilateral clefts). On the lateral lip-segments, incision is given along the planned wave like fashion and extended to the level of pyriform aperture and false attachments of orbicularis oris muscle detached from its abnormal attachments over maxilla. From the base of ala, blunt dissection was done towards the alar dome to free the mucosa from the lower lateral cartilage bilaterally followed by blunt dissection in the base of columella to separate fibres between two medial crura and medial crura and nasal mucosa. 4.0 vicryl suture is passed through the paranasal muscles and the base of the nostril, reorienting them over the premaxilla, this advances the nasal ala and forms symmetrical nostrils. The periosteum of the vomerine mucosa is dissected and elevated from the vomer cranially, to build mucosal periosteal flap for the reconstruction of nasal floor. Palatine sheet of nasal floor is formed from the mucosa of lateral aspect of intermaxillary bone with the mobilized mucoperiosteal flap of jaw stump of the lateral side. Vestibule of the maxillary bone is formed from the mucosa of middle part of the philtrum. The prolabium skin is lifted with skin hook, the orbicularis oris muscle was sutured at mid line with 3.0 vicryl sutures, over the protruded pre maxillary bone segments Then the prolabial skin was placed over the repaired muscle bed in such a fashion that it gives a good aesthetic appearance of cupid's bow. Then suturing of 
the prolabium to lateral lip segments done with 5.0 prolene suture, then the entire repaired lip is raised with skin hook, then the intra oral suturing is completed . Two small $5 \mathrm{~mm}$ cut pieces of No.14 Ryle's tube were inserted into the nostrils and secured with 3.0 silk sutures. By elevation of nose waves achieve a straight line form. Patients are not allowed per oral till 4 hours. Bottle feeding is avoided till 7 days as they are detrimental to sutures. Meticulous hygiene with betadine and topical application of soframycin on external wounds was advocated for the patient. Suture removal was done on 7 th post operative day. Post operative evaluation was done with pre and post op photographs using Frontal view and submento vertex for evaluating the parameters of lip and nose respectively.

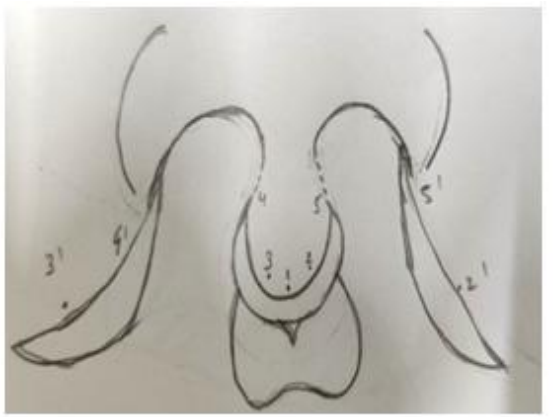

Markings

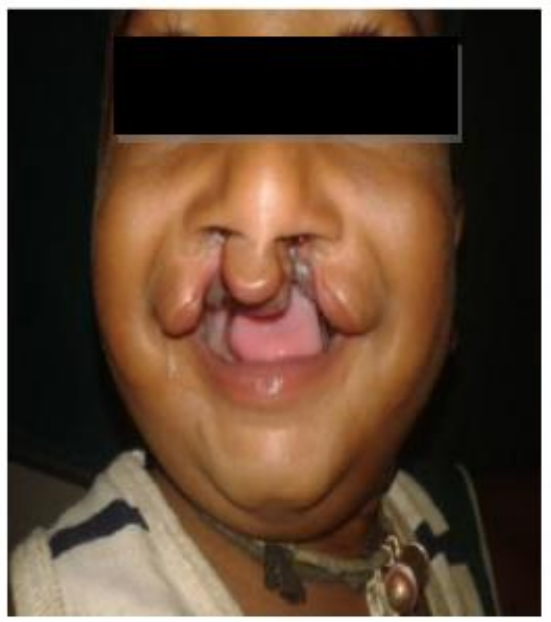

Pre- op
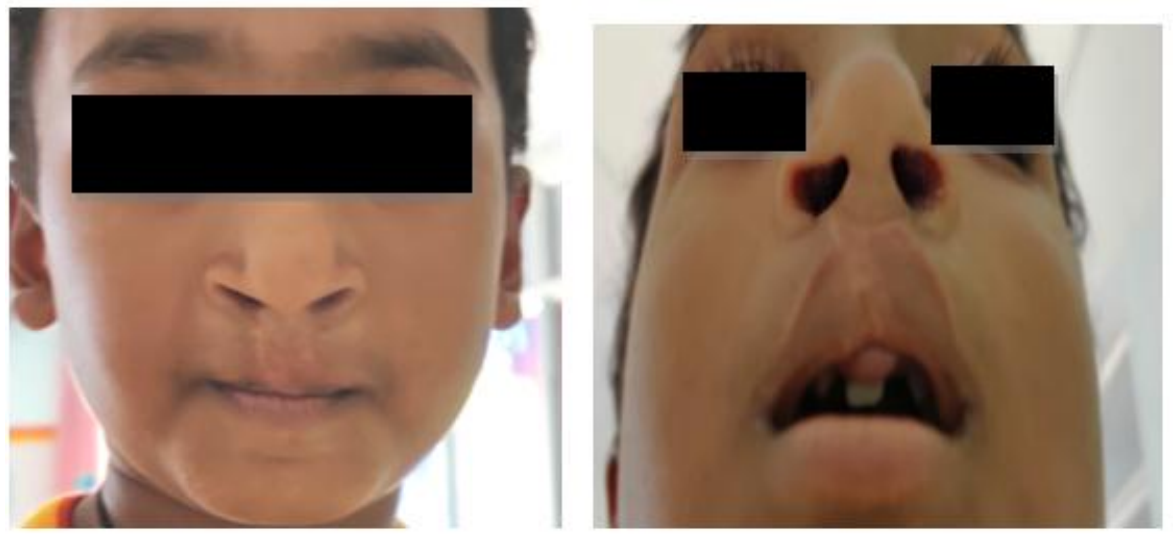

Post - op

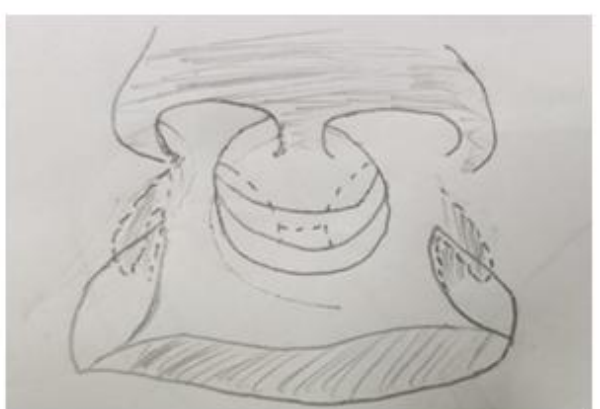

Incision design

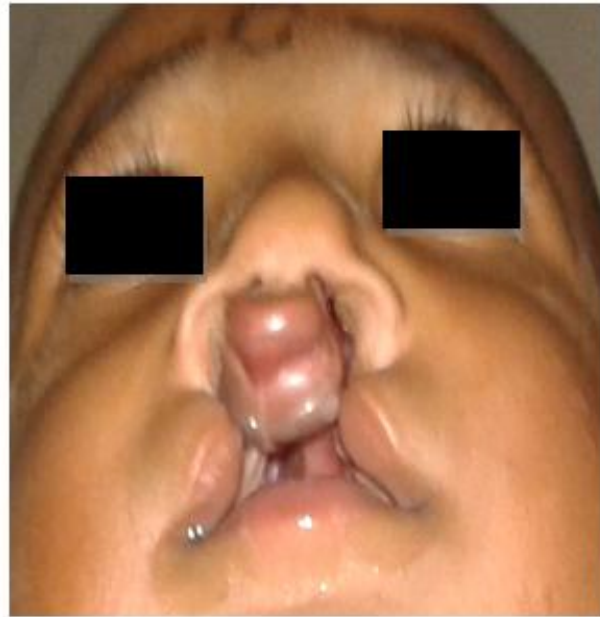

\section{DISCUSSION}

There are various techniques for cleft lip repair like Millard, Mulliken, Delaire, noordhoff... etc. pfeifer's technique has been chosen because it is a single stage procedure and has less disadvantages over other techniques. In this technique Cupid's bow is created by placing symmetrical markings and mulitiple short waves are made to elongate philtrum and collumella which helps in preserving prolabial skin for elongation of nose which in turn decreases the tension 
over operated site and prevents dehiscence. Using a wave like incision method it's easy to reconstruct the deficient vermillion than in a straight line incision. lip and nasal parameters are improved in all aspects. The case report shows the versatility and applicability of pfeifer's technique with superior post operative long term results.

\section{REFERENCES}

1. Esprasshare.org.Closure of Cleft Lips with Wave Line Incisions According to Pfeifer. Available from: http://www.esprasshare.org.
2. Reddy YS, Kumar RV, Kumar DS, Rajasekhar G, Babu VR, Reddy KS, Purna KP. Bilateral cleft lip repair-advantages of pfeifer's technique. Contemporary Clinical Dentistry. 2018 Oct;9(4):530.

3. Mathes SJ. Plastic surgery. Saunders; 2006.

4. Chigurupati R, Heggie A, Bonanthaya K. Cleft lip and palate: an overview. Oral and Maxillofacial Surgery. Oxford: Wiley-Blackwell. 2010:945-72. 